\title{
Management of Operational Efficiency: Can Indian SMEs Afford Overseeing It
}

\author{
Dr.Sangeeta Sharma ${ }^{1}$, Kunal Vashisth ${ }^{2}$, Tavishi Sharma ${ }^{3}$ \\ ${ }^{1}$ (Department of Commerce, D.A.V.Centanary College, Faridabad.INDIA) \\ 2 (Business Intelligence Consultant, Cloudsteer Technologies Pty Ltd, Gurgaon, INDIA) \\ 3 (4/4 Yr.B.Tech, Computer Science and Engineering, Lingayas University, Faridabad. INDIA)
}

\begin{abstract}
In present era of throat-cut competitiveness, the earning and growth of Indian SMEs has been deteriorating continuously and such companies are bleeding out of financial crunch. This paper examines the influence of evaluating, implementing, and accounting for the various operational efficiencies in an organization which can bring turnarounds in improving the firm's commercial and financial performances. Fifty companies were scanned for this study using well structured questionnaire as well personal contact program at various levels of organization. The results show that there is a significant correlation between the roles of various operational efficiencies within the organization that can prove to be a turnaround in enriching the commerce of the business entity. Type of corporate culture and organizational commitment do influence on the financial performance of Indian SMEs especially in densely populated auto component manufacturing companies. The propositions of the study have also been addressed. Furthermore, an attempt has also been made to improve agility, visibility, and operational performance across manufacturing. This paper is unique in dealing with the ways and means for applying six-sigma, lean-manufacturing,QMS, TQM culture for assessing business efficiency especially in SMEs in Indian Auto Component manufacturing units.
\end{abstract}

Keywords: SMEs, Operational Efficiency, Financial Performance, Turnaround, Lean-Manufacturing.

\section{Preamble}

Operational efficiency is a ratio of actual output v/s maximum output and behaves like financial leverage. It identifies wasteful processes and resources that flush off the organizational profits and can also suggest remedial design of new work processes that improve quality and productivity. Improving operational efficiency has a direct impact on a company's bottomline. Operational efficiency and lean manufacturing both target waste-elimination related to time, money, people, effort and other un-productive resources. The results are measurable, immediate and sustainable.Kaizen is a systematic approach of continuous improvement in work culture, quality, technology, production processes, productivity benchmarks, safety at workplace and leadership.

Today's customers are asking products on percent value of raw material used. High quality, low prices and timeless deliveries are best selling product features. Efficiency and Customer Satisfaction Go Hand-inHand. Under such a competitive environment, the profitability of Indian SMEs has eroded exponentially.

Manufacturers in the global landscape are facing rising competition, more product variables, more regulations, and more cost pressures than ever before in history. For agility, the enterprises have to perk up flexibility, visibility, and operational performance across their manufacturing operations. Success calls for enterprises to manage their businesses proactively\& efficiently, instead of the business issues managing them. External competitiveness is bound to increase but internal cost competitiveness is a challenge to be converted into an opportunity efficiently. Lean manufacturing is an essential component of manufacturing efficiency by building an efficient value chain, a task not easily achieved using traditional production systems. It makes use of anything less of everything compared with mass production or mass, half the manufacturing space, half the investment of equipment, design half hours a new product. DMAIC (Define, Measure, Analyze, Improve, and Control) is a process which embeds the philosophy of scaled improvement in manufacturing processes measurable. The optimal Manufacturing Operations Management solution for driving efficiency enables the integration of quality processes into the full design-manufacture-distribution cycle. Businesses can build products right the first time, removing variability of processes, while improving: manufacturing cycle time, manufacturing "touch" time, overall equipment effectiveness defect/scrap rates and first pass yields. Any type of waste from operations needs to go. Waste elimination processes typically require an organization to foster a culture where cross functional team of employees are empowered to identify the smallest incremental waste-cost factor and plug it forever under the reinforcing it through lean manufacturing and kaizen.

In this context, Spector R. (2006) highlighted that the Lean Six Sigma is the most effective in process improvement, is widely implemented in the top performing organizations. Waste elimination which is a predominant component of Lean Manufacturing can be treated as business transformation technique for creating efficiencies in a number of ways: streamlining processes, converting data into knowledge, improving services 
and correcting asset management. Controlled Process Metrics (Process Time, Wait Time, and Change over Time, First Time Quality, and Work-in-Process Inventory) are keys to improve various operational efficiencies.

Operations and Equipment Efficiency, OEE can be expressed as the product factor (availability* performance* quality) where Availability stands for operating time, Performance is designed cycle time and Quality is salable units produced.

Commerce of operational efficiency shows how to achieve enterprise-wide supply chain visibility, manufacturing synchronization, and control over efficiency through an integrated system that directly addresses manufacturing competence at a reduced cost of goods. This innovative approach bridges the gap between the "silos" of information that impede legacy systems and point solutions.

The commerce of business efficiency can be better achieved with cost reduction techniques categorized as under:

$>$ Financial Management: Cost estimations, planning, budgeting, cash management, product costing and business restructuring.

$>$ Relationship Management: JV's, Tie ups, Franchisee, Strategic partnerships, productive employees, performance rewards.

> Marketing Management: Aggressive and guerrilla selling, Floating pricing and RFQ's for vendor needs, Customer referral, retention, loyalty and exchange of goods.

As our intention is to demonstrate the benefits of running of business based on commerce of efficiencies, our attempt is to understand the usage Lean manufacturing/six sigma and other cost reduction techniques in Indian SMEs, especially in auto OEMs. We then present more detailed overview of improved business efficiencies based on respondents' feedback. Finally, we discuss some of lessons learnt during this entire research followed by implications of this study in enhancement of profitability of SMEs.

\section{Review Of Related Transcription}

Improving operational efficiency through lean manufacturing has been a buzz word since last decade in Indian Industries yet it is not successfully implemented. McDuffie (1995) analyzed that the operational changes alone do not yield expected benefits without a "bundle" which includes structural, managerial and cultural changes. Structural changes have further supported by Hambleton (2008), highlighted the essence of improved layout of the workplace/shop floor contributes for increasing productivity of the workers, through more economical use of hand movements by conducting an experiment on hacksaws assembly. It has been shown to outperform the traditional production model of large batches on several occasions (Boyer et al. 1997; Nakamura et al. 1998) and just in time (JIT) supply has is being practiced in manufacturing industries. While being studying various derives at Toyota, Krafcik, (1998) describes the Japanese-style manufacturing process pioneered by Toyota, which uses a wide range of methodologies including just-in-time inventory systems, continuous improvement, and quality circles. Czarnecki and Loyd (1998) recognized waste as non value added activities which can be eliminated through continuous improvement by at the pull making the customer in pursuit of perfection. Garnett et al. (1998) suggested that lean is not simply a method that can be applied in any industry and bring the benefits at par with Toyota. The common mistake made by organizations is focusing wholly on their operations while being unable to have a wider perspective and capability to position them in the whole value chain (Yamashita, 2004). Furthermore, the study of Russell and Taylor (1999) exhibits that the major purposes of using lean production is to increase productivity, improve product quality and manufacturing cycle time, reduce inventory, reduce lead time and eliminate manufacturing waste. A study of employee's reaction to change into self-managed work teams showed employees' expectations were critical for their satisfaction and commitment, Shapiro \& Kirkman (1999). Commenting on lean manufacturing, Yeung and Chan (1999) suggested that the manufacturers are becoming increasingly aware of the importance of modern management philosophy in providing them with a competitive advantage in a free market system. Niemes (1999) suggests that companies can apply Six Sigma principles to the reengineering of sales and marketing operations for improving the bottom-line.

Carlivati (2007), highlighted that design for production goes a major step further and aims to reduce ship production costs to a minimum, while simultaneously complying with both owner and classification society rules. The vessel must "fulfill its operational functions with acceptable safety, reliability and efficiency"

Successful applications of DMAIC leads to improved customer relationships, reductions in marketing costs, and ultimately, increasing profits. In this context Donath (2005) highlighted that Six Sigma can lead to improved customer relationships by improving the process that delivers the product or service to the customer thereby enhancing the firm's commercials.

Thus, lot of literature is available on operational efficiency improvement tools like Leanmanufacturing, six-sigma, DMAIC, 5-S, Kaizens etc., yet I have not come across any study which can benefit Indian SMEs in improving the efficiency of various operation for enriching its bottomline. 


\section{Need Of The Study}

Profitability is a barometer for measuring efficiency and economic prosperity of any business entity. Profit maximization is not clearly understood by Indian companies as the process of identifying the most efficient manner of obtaining the highest rate of return from its production model. SME's which are focusing more on value additive activities compared to non-value addition activities like waste-elimination are failing miserably on this front. As we have not come across such type of study especially for Indian Auto SMEs, an attempt is being made to understand, analyze, interpret and conclude the solution to this burning issue of improving overall business efficiency of Indian SMEs operating in one of the largest manufacturing sectorIndian automobile industry.

\section{Objectives}

Profits help strengthening and broadening the capital- and-assets base of business and ensure its future growth, and for enhancing its ability to absorb shocks and set-backs common in business. The purpose of this paper is to provide new insights to the Indian SME's (especially for the companies in automobile industry) in the domain of creation and sustaining profit by redefining operation-technology under the umbrella of lean manufacturing. Following are the main objectives of the study:

1) To understand that the Indian SMEs are putting their best for implementing various derives like working in lean manufacturing and kaizen culture, using Information Technology for budgetary control, MIS and data analysis for faster decision making.

2) To understand and evaluate how large scale OEMs are helping the SMEs suppliers for improving the operational efficiency of SMEs.

\section{Research Design}

The study was limited to the companies in geographical domain of NCR-Delhi. These companies belong to Indian automotive industry and fall under SMEs category, have sample size as per Table-1.

\section{TABLE: 1 SAMPLE SIZE OF COMPANIES UNDER STUDY}

\begin{tabular}{|c|l|c|c|}
\hline \multirow{2}{*}{ S.No. } & \multicolumn{1}{|c|}{ CATAGORY OF MANUFACTURER } & \multirow{2}{*}{ SIZE } & \multirow{2}{*}{ PERCENT } \\
\hline 1 & Forge Auto Component Manufacturer & 4 & 10 \\
\hline 2 & Casted Auto Component Manufacturer & 10 & 25 \\
\hline 3 & Sheet Metal Auto Component Manufacturer & 10 & 25 \\
\hline 4 & Tool and Die makers & 6 & 15 \\
\hline 5 & Fabricator of Auto Component & 4 & 10 \\
\hline 6 & General Engineering Auto Component Manufacturer & 6 & 15 \\
\hline & TOTAL & 50 & 100 \\
\hline
\end{tabular}

The categories of manufacturers have been selected in a ratio such that the product manufactured are being used to assemble an automobile are in array of its importance. As castings and sheet metal constitute a major share in automobile, the consideration of such manufacturers in sample size has been assigned 25 percent. Based on above sample size, well structured questionnaire was designed to judge the context at various levels of hierarchy in the organization. This way, certain questions were asked for cross verification of facts stated by various hierarchies. Based on data, following hypotheses was generated for strengthening the study.

H01: Indian SMEs deploy Lean manufacturing, QMS, Kaizen and IT-Tools for enhancing OEE.

H02: OEMs always initiate drives for improving operational efficiency of Indian SMEs.

Above hypotheses have been tested for drawing conclusive result. The implication and limitation of the study have been spelled well.

\section{Analysis and Interpretation}

Designed questionnaire was floated to the three hierarchies, that is, Managers, Supervisors and skilled operators for getting feedback. Personal contact program was more successful in getting responses on leanconcepts. The responses of various team members have been piled up in Table-2.

Table-2: RESPONSE OF HIERARCHIES ON LEAN-CONCEPTS

\begin{tabular}{|c|l|c|c|c|}
\hline S.No & \multicolumn{1}{|c|}{ DESCRIPTION OF PARAMETER } & MANAGER & SUPERVISOR & OPERATOR \\
\hline 1 & 5-S and DMAIC are operational at work & 18 & 12 & 10 \\
\hline 2 & Your processes are regularly validated & 22 & 10 \\
\hline 3 & Do you measure process capability(Cpk) & 14 & 8 & 18 \\
\hline 4 & Productivity is preferred over Production & 22 & 8 & 4 \\
\hline 5 & Company does not have inventory store & 10 & 12 & 8 \\
\hline 6 & Your delivery rating exceeds 90\% & 18 & 8 \\
\hline
\end{tabular}


Management of Operational Efficiency: Can Indian SMEs Afford Overseeing It

\begin{tabular}{|c|l|c|c|c|}
\hline 7 & Do you treat rejection/rework/waste & 12 & 13 & 6 \\
\hline 8 & Do you target rejection as ppm & 22 & 14 & 8 \\
\hline 10 & O.E.E and Yields are regularly monitored & 12 & 8 & 0 \\
\hline 11 & Company has nil accidents & 28 & 22 & 12 \\
\hline & TOTAL & 178 & 129 & 64 \\
\hline & OVERALL PERCENT & 31 & 29 & 15 \\
\hline
\end{tabular}

Table-2 exhibits that managers and supervisors do understand the lean concept and its implementation as low as thirty percent while operators have responded to fifteen percent only. Despite of this there is a big gap among various hierarchies in understanding the various aspects of lean manufacturing in Indian SMEs.

Responses of respondents regarding QMS practices have been arranged in Table-3 below.

TABLE-3: RESPONSE ON QMS PRACTICES

\begin{tabular}{|c|l|c|c|c|}
\hline S.No & DESCRIPTION OF PARAMETER & MANAGER & SUPERVISOR & OPERATOR \\
\hline 1 & Company is accredited to QMS & 38 & 32 & 32 \\
\hline 2 & Rejection increases Production target & 22 & 28 & 34 \\
\hline 3 & Company send you for outstation training & 16 & 8 & 0 \\
\hline 4 & In plant Training is regularly imparted & 22 & 18 & 12 \\
\hline 5 & Company celebrates improvement plans & 12 & 6 & 2 \\
\hline 6 & Best worker awards are regularly given & 18 & 16 & 12 \\
\hline 7 & Rework is not a regular practice in company & 18 & 9 & 6 \\
\hline 8 & Company's layout is work supportive & 22 & 16 & 6 \\
\hline 9 & Customers often witness process audit & 24 & 18 & 8 \\
\hline 10 & Do you know and understand TQM & 40 & 32 & 14 \\
\hline 11 & Do you follow TQM Practices & 9 & 8 & 4 \\
\hline 12 & Do you exercise cost reduction techniques & 30 & 20 & 14 \\
\hline 13 & There is an effective suggestion scheme & 32 & 18 & 12 \\
\hline & TOTAL & 303 & 229 & 156 \\
\hline & OVERALL PERCENT & 58 & 44 & 30 \\
\hline
\end{tabular}

Table-3 highlights that management of Indian SMEs do take interest in going for some or the other quality standard which is evident from the enquiry of supervisors (forty four percent favorable responses) and operators have spelled thirty percent positive on this aspect. Though there is a big gap between all three categories, yet Indian SMEs prefer going for implementing Quality Management System.

Investigation was made further to understand the understanding and implementation of Kaizen Practices in the companies. Data recorded has been arranged in Table- 4 .

TABLE-4: IMPLEMENTATION OF KAIZEN

\begin{tabular}{|c|c|c|c|c|}
\hline S.No & DESCRIPTION OF PARAMETER & MANAGER & SUPERVISOR & OPERATOR \\
\hline 1 & Does the company have area-owners for 5-S & 22 & 18 & 16 \\
\hline 2 & Company has planned calendar for kaizen & 18 & 12 & 10 \\
\hline 3 & Kaizens eliminates wastes & 18 & 12 & 10 \\
\hline 4 & Does kaizen decrease manufacturing cost & 22 & 18 & 12 \\
\hline 5 & Are cross functional core teams in place & 12 & 11 & 10 \\
\hline 6 & Kaizen reduces scrap & 36 & 40 & 36 \\
\hline 7 & Kaizens improve operational efficiency. & 36 & 40 & 36 \\
\hline 8 & Good environment is bye product of kaizen & 18 & 12 & 10 \\
\hline 9 & Kaizen attracts customers confidence & 28 & 32 & 18 \\
\hline \multirow[t]{3}{*}{10} & Kaizen improves productivity & 18 & 12 & 10 \\
\hline & TOTAL & 228 & 207 & 168 \\
\hline & OVERALL PERCENT & 57 & 52 & 42 \\
\hline
\end{tabular}

It can be inferred from table-4 that fifty seven percent managers, fifty two percent supervisors and forty two percent operators do favor in going for kaizens and overall fifty percent of total team put effort in this direction.

The research further investigated the usage of Information Technology in controlling the budget of the company. The responses have been arranged in table-5, below.

TABLE-5: RESPONSE ON USAGE OF INFORMATION TECHNOLOGY TOOLS

\begin{tabular}{|c|l|c|c|c|}
\hline S.No & \multicolumn{1}{|c|}{ DESCRIPTION OF PARAMETER } & MANAGER & SUPERVISOR & OPERATOR \\
\hline 1 & Company uses some or other ERP & 14 & 14 & 12 \\
\hline 2 & IT-Usage ease decision making & 36 & 32 & 16 \\
\hline 3 & IT Techniques reduces Report/MIS time & 36 & 32 & 16 \\
\hline 4 & Company uses IT in periodic budgeting & 18 & 12 & 6 \\
\hline 5 & IT-Usage helps in daily SWOT analysis & 26 & 24 & 2 \\
\hline
\end{tabular}


Management of Operational Efficiency: Can Indian SMEs Afford Overseeing It

\begin{tabular}{|c|c|c|c|c|}
\hline 6 & Information technology reduces cost & 32 & 28 & 28 \\
\hline 7 & Bill of material is better improved by IT & 28 & 22 & 12 \\
\hline 8 & Usage of IT decreases overall cost & 14 & 12 & 12 \\
\hline 10 & Does company uses Cloud computing & 2 & 0 & 0 \\
\hline 11 & IT Tools are effective in competitiveness & 34 & 32 & 18 \\
\hline & TOTAL & 240 & 208 & 122 \\
\hline & OVERALL PERCENT & 55 & 47 & 28 \\
\hline
\end{tabular}

It can be learnt from table-5 that more than fifty percent of the companies do recognize that usage of Information Technology like ERP/SAP/Cloud Computing really serve as an aid in budgetary control, preparing MIS and other reports.

Data in table-6 pertains to the role of OEMs which are customers of SMEs, in improving the overall efficiency of SMEs operations.

TABLE-6: RESPONSES ON OEMS IN IMPROVING OPERATIONAL EFFICIENCY

\begin{tabular}{|c|c|c|c|c|}
\hline S.No & DESCRIPTION OF PARAMETER & MANAGER & SUPERVISOR & OPERATOR \\
\hline 1 & OEMs can make you productive & 36 & 32 & 40 \\
\hline 2 & OEMs conduct development programs regularly & 12 & 12 & 2 \\
\hline 3 & You are audited by OEMs as surprise & 8 & 4 & 2 \\
\hline 4 & OEMs do not bother about you & 18 & 22 & 28 \\
\hline 5 & You visit OEMs for training programs & 10 & 6 & 4 \\
\hline 6 & You are awarded by OEMs at year end & 21 & 18 & 16 \\
\hline 7 & Company is on-line with OEMs & 10 & 6 & 2 \\
\hline 8 & OEMs press you for technology up gradation & 18 & 22 & 24 \\
\hline 9 & OEMs does not bother about you at all & 14 & 10 & 10 \\
\hline 10 & OEMs ask you for Quality,cost,delivery & 36 & 32 & 32 \\
\hline 11 & OEMs press you for cost reduction & 36 & 32 & 32 \\
\hline \multirow[t]{3}{*}{12} & OEMs do guide you for enhancing profitability & 14 & 16 & 10 \\
\hline & TOTAL & 233 & 212 & 202 \\
\hline & OVERALL PERCENT & 48 & 44 & 42 \\
\hline
\end{tabular}

Table-6 exhibits that OEM customers do put certain efforts in developing the SMEs such that it becomes operationally efficient. Under this, more or less, all three categories of employees resembles in accepting the fact that OEMs are coming forward to develop its suppliers on operational front. Still efforts are less than half way of desired level.

For summarizing the views of all respondents under the various parameters have been piled up in the form of table-7.

TABLE-7: VIEWS ON OVERALL OPERATIONAL EFFICIENCY

\begin{tabular}{|c|c|c|c|c|c|}
\hline S.No & OVERALL ASSESSMENT & MANAGERS & SUPERVISOR & OPERATOR & RANGE \\
\hline 1 & Implementing of lean-Mfg. & 31 & 29 & 15 & 16 \\
\hline 2 & Top managements motivates for QMS & 58 & 44 & 30 & 28 \\
\hline 3 & Usage of IT in budgetary controls & 55 & 47 & 27 & 28 \\
\hline 5 & OEMs derives for Operations Efficiency & 48 & 44 & 42 & 6 \\
\hline & TOTAL & 249 & 216 & 157 & \\
\hline & OVERALL PERCENT & 50 & 43 & 31 & 19 \\
\hline
\end{tabular}

It can be revealed from table-7 that on an average; fifty percent of managers, forty three percent of supervisors and thirty one percent of operators really understand and implement the various aspects of enhancing operational efficiency.

\section{Discussion}

Table-7,highlights that there is a significant variation of thought process i.e.by sixteen percent for implementing lean, twenty-eight percent in going for QMS and IT-Tools and overall, all three categories differ by twenty-four percent. Thus, it is in contrary with null hypothesis, H01, and alternate hypothesis that is Indian SMEs don't deploy Lean manufacturing, QMS and IT-Tools for enhancing operational efficiency is true. Likewise, SMEs employees at various hierarchies in organization believe that there is a variation of fifteen percent in case of implementing kaizen and six percent in case of stating that OEMs do put necessarily adequate efforts in improving the operational efficiencies of its SME suppliers in automobile industry. This is not in line 
with hypothesis,H02, and alternate hypothesis i.e.SMEs are not adopting Kaizen practices to a sufficient level and OEMs derives fall short of length in enhancing the operational efficiency of SMEs is true.

While interpreting overall effect of various parameters, it has been noticed that forty-two percent employees do understand and implement the drives for enhancing operational efficiency and there is a big gap of nineteen percent among various employees on this aspect. Thus, studying combined effect of all parameters, the null hypotheses, $\mathrm{H} 01$ and $\mathrm{H} 02$ fails to stand straight.

\section{Conclusion}

It is a true fact that Indian SMEs need to enhance the operational-efficiency for the survival in a competitive automobile industry. Indian SMEs are miserably failing in implementing minimum necessary required practices like lean manufacturing, kaizen, IT-Tools, budgetary control in manufacturing, QMS and TQM culture in their operations. Firstly, SMEs need to implement the above practice as necessity not as luxury. Secondly, it has been noticed that there exists a big gap in thinking among managers, supervisors which further widens up in case of operators as far as understanding and implementing efficiency-enhancement programs are concerned. This lack of team work has been seen as a big challenge in these directions.

Thirdly, OEMs sets so many stringent restrictions regarding manufacturing process control and don't impart necessary support and trainings to absorb the drives. There is great expectation from large sector OEMs towards putting up adequate efforts for making SME supplier technology-reliant and optimally trained for discharging efficiencies.

Precisely, as cost of inputs and sale being competitive and market driven, enhancing the operational efficiency is only way where visibility of organizational wealth can be unveiled SMEs for being competitive and present in global market place.

\section{Limitation And Futuristic Scope Of Study}

As the study was self sponsored and no external aid was taken and keeping financial constraints in mind, the study was limited to NCR-Delhi region in the domain of automobile industry. This is an opportunity for any other researcher to take coverage of pan India. As the study is limited to the operational efficiency of SMEs in automobile industry in India, the topic can be further broadened in other industries also. Furthermore, this research study concludes the joint effect of managers, supervisors and operator opens up a field for making it on individual basis.

\section{References}

[1]. Boyer, K. K., G. K. Leong, et al. (1997). "Unlocking the potential of advanced manufacturing technologies." Journal of Operations Management15 (4): 331-347.

[2]. Carlivati, P. (2007), "Six Sigma: a new path to perfection", ABA Bank Marketing, No. April, pp.24-9.

[3]. Czarnecki, H. and Loyd, N.,( 2004). Simulation of Lean Assembly Line for High Volume Manufacturing, Research Paper Published by University of Alabama in Huntsville.

[4]. Donath, B. (2005), "Six Sigma's true meaning lies with customer", Marketing News, No. May, pp.9-10.

[5]. Firka, D. (2010), "Six Sigma: an evolutionary analysis through case studies", The TQM Journal, Vol. 22 No.4, pp.423-34.

[6]. Hambleton, L. (2008), A Treasure Chest of Six Sigma Growth Methods, Tools, and Best Practices, Prentice-Hall, Upper Saddle River, NJ .

[7]. Kazuhiro Yamashita, (2004). Implementation of Lean Manufacturing Process to XYZ Company in Minneapolis Area, Master Thesis, University of Wisconsin-Stout.

[8]. Krafcik, J.F. Triumph of the Lean production system. Sloan Management Review 1998; 30 (1); 41-53

[9]. Lim, J., Hoffmann, E. Appreciation of the zone of convenient reach by naive operators performing an assembly task. International Journal of Industrial Ergonomics 1997; 19; 187-199.

[10]. McDuffie, J. P. (1995). "Human Resource Bundles and Manufacturing Performance: Organizational Logic and Flexible Production Systems in the World Auto Industry." Industrial and Labour Relations Review 48(2): 197-221

[11]. Niemes, J. (1999), "Taking sales success to new heights with Six Sigma", National Productivity Review, No. Autumn, pp.37-41.

[12]. Russell, RS. and Taylor, B.W. (1999). Operations Management, 2nd Edn, Uppers Saddle River, NJ: Prentice Hall.

[13]. Shapiro, D. L. and B. L. Kirkman (1999). "Employees' reaction to the change to work teams." Journal of Organizational Change Management12 (1): 51-67.

[14]. Spector, R. (2006), "How constraints management enhances lean and six sigma”, Supply Chain Management Review, Vol.10 No.1, pp.42-7.

[15]. Yeung, CL and Chan, L.Y. (1999). Towards TQM for Foreign Manufacturing Firms Operating in Mainland China, International Journal of Quality and Reliability Management, 16, (8), 756-771. 